\title{
AISI 1010 Malzemesinin Sürtünmeli Delinmesinde Optimum Parametrelerin Gri İlișkisel Analiz Yöntemiyle Belirlenmesi
}

\section{Latif ÖZLER*}

Firat ÜniversitesiMühendislik Fakültesi Makine Mühendisliği Bölümü, Elazı̆̆

lozler@firat.edu.tr

Öz: Bu çalışmada AISI 1010 kare kesitli malzeme CNC freze tezgâhında farklı sürtünme açılarına sahip sürtünmeli delme matkabı ile delinmiş ve işlem değişkenleri ile performans çıktıları arasındaki ilişki Gri İlişkisel Analiz Yöntemi (GRA) kullanılarak incelenmiştir. Deney parametreleri olarak 50, 75 ve $100 \mathrm{~m} /$ dak delme hızları, 75, 150 ve $225 \mathrm{~mm} /$ dak ilerlemeler ve 30,45 ve $60^{\circ}$ sürtünme açıları seçilmiş ve deliklerin yüzey pürüzlülükleri ile kovan yükseklikleri ölçülmüştür. Deney sonuçlarına göre delme hızı ve ilerleme artıkça yüzey pürüzlülüğü azalmıştır. Matkap sürtünme açısındaki artış yüzey pürüzlülüğünü artırarak kovan yüksekliğini azaltmıştır. Gri İlişkisel Analiz Yöntemine göre sürtünmeli delme işlemindeki optimum işlem parametreleri; delme hızında $100 \mathrm{~m} /$ dak, ilerlemede $225 \mathrm{~mm} /$ dak ve sürtünme açısında $30^{\circ}$ elde edilmiştir. Değişken işlem parametrelerinin çoklu performans üzerindeki önemi sırası ise B3> A1> C3 şeklinde olup $100 \mathrm{~m} / \mathrm{dak}$ delme hızı, $30^{\circ}$ sürtünme açısı ve $225 \mathrm{~mm} /$ dak ilerleme olarak elde edilmiştir.

Anahtar kelimeler: Sürtünmeli delme, GRA, Yüzey pürüzlülüğü, kovan yüksekliği.

\section{Determination of Optimum Parameters in Friction Drilling of AISI 1010 steel by Grey Relational Analysis}

\begin{abstract}
In this study, AISI 1010 square section material was drilled with friction drill at different drill bit angles on CNC milling machine and the relationship between process variables and performance outputs was investigated by using Grey Relational Analysis Method (GRA). Drilling speeds of 50, 75 and $100 \mathrm{~m} / \mathrm{min}$, feed rates of 75, 150 and $225 \mathrm{~mm} / \mathrm{min}$, and friction end angles of 30,45 and $60^{\circ}$ were selected as the test parameters and the surface roughness and bushing heights of the holes were measured. According to the experimental results, the surface roughness decreased as the drilling speed and feed rate increased. The increase in drill bit angle increased surface roughness and reduced bushing height. According to GRA Method optimum process parameters in friction drilling were obtained as $100 \mathrm{~m} / \mathrm{min}$ at drilling speed, $225 \mathrm{~mm} / \mathrm{min}$ at feed rate and $30^{\circ}$ at friction cone angle. The importance ranking of variable process parameters are as B3> A1> C3 with a drilling speed of $100 \mathrm{~m} / \mathrm{min}$, a friction angle of $30^{\circ}$ and a feed of $225 \mathrm{~mm} / \mathrm{min}$
\end{abstract}

Key words: Friction drilling, GRA, Surface roughness, Bushing height

\section{Giriş}

Günümüzde kesit kalınlığı ince olan parçaların bağlantıları endüstride ve özellikle imalat alanında oldukça önemli bir yer tutmaktadır. Öncelikle ince kesitli parçaların bağlantılarında kesit kalınlığının yeterli seviyede olmaması nedeniyle kaynak birleştirmelerde bağlantı bölgesinde aşırı erime, delik delme esnasında delik bölgesinde deformasyon ve yırtılma gibi önemli problemler ortaya çıkmaktadır[1]. Yine ince kesitli vidalı bağlantılarda parçaların et kalınlığının az olması nedeniyle yeterli vida diş boyu uzunluğu sağlanamaması da ayrıca önemli bir sorun teşkil etmektedir[1,2]. Bu nedenle sürtünmeli delme işlemi bu tür problemleri ortadan kaldırıp, vidalı bağlantılarda cıvataların sıkma yükünü artırmak için kovan oluşturmaktadır(Şekil 1.1). Sürtünmeli delme, dönen bir takım ile malzeme arasındaki termal sürtünmeyle oluşan 1sı yardımıyla yumuşayan iş parçasının deformasyonla içine ekstrüze olması ve ince duvarlı bir kovan oluşturarak delik açılması işlemidir[3-5]. Bu işlemin en önemli avantajı delme zamanın kısa ve takım ömrünün ise uzun olmasıdır[4]. Sürtünmeli delme işlemi ile ilgili yapılan çalışmalara göre sürtünmeli karbür matkap uçlarının helisel karbür matkap uçlarından daha iyi performansa sahip olduğu, ömürlerinin helisel karbür matkap uçlarına göre oldukça uzundur[4,5]. AISI 1018 malzemesinin sürtünmeli karbür matkap ucu ile delinmesinde 1000 den fazla delik açacak kadar dayanıklı olduğu, aşınmanın konik kısımda çok az miktarda meydana geldiği yine silindirik kısmın aşınmadan etkilenmediği belirtilmiştir[2]. Düşük karbonlu çeliklerin karbür sürtünmeli delme matkabıyla delinmesinde 11.000 delik sonrası bile aşınmanın minimum seviyede olduğu tespit edilmiştir[6]. Bununla birlikte sürtünmeli delme işlemi ile delinen

\footnotetext{
* Sorumlu yazar: lozler@ firat.edu.tr. Yazarın ORCID Numarası: 0000-0002-0595-153X
} 
deliklerde ayna gibi bir yüzey kalitesi de elde edildiği belirtilmiştir[5]. Delme işlemi sonucu oluşan kovan, iş parçası kalınlığının 3-5 katı kalınlığa kadar yüksekliğe ulaşır[5-7]. Kovan oluşumunu etkileyen en önemli faktör ise takım iş parçası ara yüzey sıcaklığıdır[8].

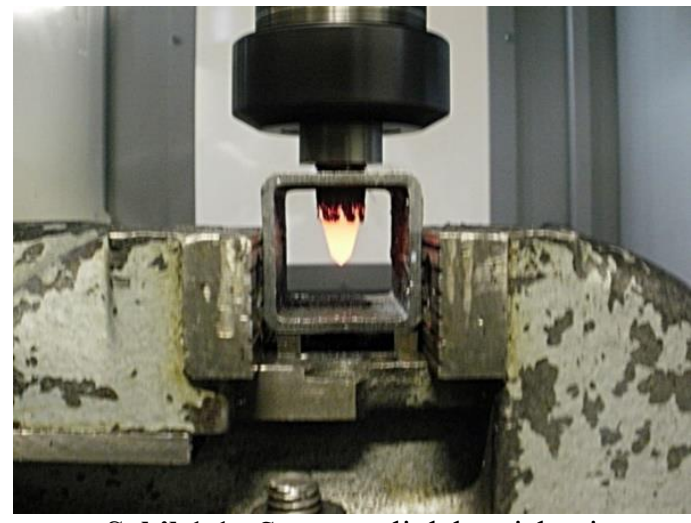

Şekil 1.1. Sürtünmeli delme işlemi

Sürtünmeli delme ile ilgili çalışmalarda genellikle kaplamalı ve kaplamasız karbür sürtünmeli delme matkapları kullanılmış ve bu çalışmalarda takım iş parçası temas yüzeyi sıcaklı̆̆ı, ilerleme kuvveti, kovan profilleri ve delik yüzey pürüzlülükleri incelenmiştir[5,7-9]. Bununla birlikte sürtünmeli delme ile ilgili yapılan başka bir çalı̧̧mada ise HSS matkap ucu kullanılarak, A7075-T651 malzemesi ön deliksiz ve ön delikli olmak üzere iki şekilde sürtünmeli delinmiş ve takım iş parçası temas sıcaklığı, kovan yüzey pürüzlülüğü ve kovan profilleri incelenmiştir[10]. Ayrıca sürtünmeli delme ile ilgili çalışmalarda mikro sertlik ve mikro yapısı ile ilgili birkaç çalışma da mevcuttur[11-13]. Bu çalışmalarda Alüminyum ve titanyum alaşımları sürtünmeli delme yöntemiyle delinmiş ve isıdan etkilenen bölgelerin mikro yapıları, mikro sertlikleri ve kesici takım aşınma tipleri incelenmiştir.

Sürtünmeli delmede işlem parametrelerini optimizasyonu ile ilgili yapılan birkaç çalışma mevcuttur. ElBahloul ve ark.[14] tarafından yapılan bir çalışmada AISI 304 paslanmaz çelik malzeme sürtünme delme matkabıyla delinmiş ve deney parametrelerinin eksenel ve radial kuvvete, delik çapına, delik yuvarlaklığına ve kovan yüksekliğine etkisi bulanık mantık tekniği (fuzzy logic technique) kullanarak incelenmiş̧ir. Çoklu performans özelliklerini etkileyen en önemli parametrelerin devir sayısı ile iş parçası kalınlı̆̆ının olduğu ifade edilmiş̧ir. Optimum işlem parametreleri ise ilerlemede $100 \mathrm{~mm} / \mathrm{dak}$, devir sayısının 3600 dev/dak, takım temas yüzey alanın $\% 50$ ve sürtünme uç açısının $45^{\circ}$ olduğu ifade edilmiştir. El-Bahloul ve ark. [15] tarafindan yapılan başka bir optimizasyon çalışmasında ise AISI 304 paslanmaz çelik malzeme sürtünme matkap ile delinmiş ve termo-mekanik modelleme yapılmıştır. Ayrıca çalışmada performans karekterleri bulanık mantık tekniği ile optimize edilmiștir. En iyi işlem parametrelerinin $60 \mathrm{~mm} /$ dak ilerleme, 3600 dev/dak devir sayısı, \%50 takım temas yüzey alanın ve $30^{\circ}$ sürtünme uç açısının şeklinde olduğu ifade edilmiştir. Ku ark.[16] tarafından yapılan optimizasyon çalışmasında ise yine AISI 304 paslanmaz çelik malzeme delinmiş ve işlem parametrelerinin yüzey pürüzlülüğüne etkisini incelenmiştir. Çalışmada Taguchi deney tasarımı yapılmış ve işlem parametreleri Varyans Analizi(ANOVA) yardımıyla optimize edilmiştir. Elde edilen sonuçlara göre sürtünme açısı ve iş mili devir sayısının yüzey pürüzlülüğ̆̈nü üzerinde önemli etkiye sahip olduğu ifade edilmiştir. Burç uzunluğu açısından sürtünme temas alanın önemli olduğu ve \%75 temas alanına sahip uçlarla daha yüksek burç uzunluğunun elde edildiği ifade edilmiş̧ir. Ayrıca optimum parametreler $45^{\circ}$ uç açısında , $\% 75$ sürtünme açısında, $100 \mathrm{~mm} / \mathrm{dak}$ ilerlemede ve $2400 \mathrm{dev} / \mathrm{dak}$ devir sayısında elde edildiği ifade edilmiştir.

Talaşlı üretimin yaklaşık \% 40 'ınu oluşturan delme işlemlerinde işleme parametreleri önceden belirlenir ve bu doğrultuda sabit kesme hızı ve ilerleme değerleri kullanılarak üretim yapılır. Parametrelerin doğru belirlenmesi takım ömrünü ve yüzey kalitesini artırarak işleme zamanı kısaltır. Araştırmacılar işleme zamanını azaltmak ve yüzey kalitesini iyileştirmek amacıyla bir takım çalışmalar yapmış ve farklı delme parametreleri kullanmışlardır. Literatür çalışmaları incelendiğinde sürtünmeli delme yöntemi kullanılarak bir takım çalışmalar yapılmış ve takım iş parçası ara yüzeyi bölgesi sıcaklığı, delme kuvveti, yüzey pürüzlülüğü, mikro yap1 ve kovan profilleri incelenmiştir. Bununla beraber literatürde AISI 1010 iş parçasının sürtünmeli delinmesinde Gri ilişskisel analiz(GRA) yöntemi kullanılarak çoklu performansın(yüzey pürüzlülüğü ve kovan yüksekliği) değerlendirilmesi ile ilgili bir araştırma yoktur. Bu nedenle, bu çalışmada sürtünmeli delme parametrelerinin performans çıktıları üzerindeki etkilerini bulmak için Gri sistem teorisi uygulandı. Gri ilişkisel analiz(GRA) ve Gri ilişkisel derece yardımıyla(GRD) optimum delme parametreleri elde edildi. 


\section{Materyal ve Yöntem}

Bu araştırmada 2 mm et kalınlığındaki kare kesitli AISI 1010 malzemesi sürtünmeli matkapla delinerek, delme parametrelerinin kovan yüzey pürüzlüğüne ve delik kovan yüksekliğine etkisi incelenmiştir. Delme işlemlerinde \%10 Co ihtiva eden $6 \mathrm{~mm}$ çapında K20 tipi kaplamasız sinterlenmiş karbür uçlar kullanılmıştır. Sürtünmeli delme matkap uçları ve $30^{\circ}, 45^{\circ}$ ve $60^{\circ}$ sürtünme açısına sahip olup sürtünme temas yüzey alanı oranı $\%$ 100( Şekil 2.1). AISI 1010 iş parçasının kimyasal özelliği Tablo 1'de, sürtünmeli delme parametreleri Tablo 2 de verilmiştir.

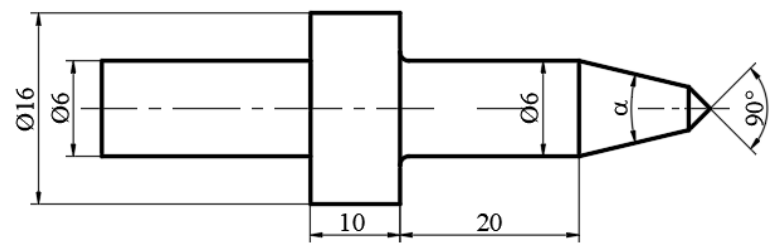

Şekil 2.1. Deneylerde kullanılan sürtünmeli matkap

Tablo 1. AISI 1010 çeliğin kimyasal bileşimi

\begin{tabular}{ccccccccc}
\hline \multicolumn{10}{c}{ Alaşım elementleri (\%) } \\
\hline $\mathrm{C}$ & $\mathrm{Si}$ & $\mathrm{Mn}$ & $\mathrm{Cu}$ & $\mathrm{S}$ & $\mathrm{Cr}$ & $\mathrm{Ni}$ & $\mathrm{Al}$ & $\mathrm{Fe}$ \\
0.0475 & 0.0312 & 0.2107 & 0.0276 & 0.0182 & 0.0233 & 0.0160 & 0.0318 & 99.455 \\
\hline
\end{tabular}

Tablo 2. Sürtünmeli delme parametreleri ve seviyeleri

\begin{tabular}{|c|c|c|c|c|c|}
\hline \multirow{2}{*}{ Delme parametreleri } & \multirow{2}{*}{$\begin{array}{c}\text { Faktör } \\
\text { sembolü }\end{array}$} & \multirow[t]{2}{*}{ Birim } & \multicolumn{3}{|c|}{ Seviye } \\
\hline & & & I & II & III \\
\hline Matkap uç sürtünme açısı & $\mathrm{A}$ & Derece $\left(^{\circ}\right)$ & 30 & 45 & 60 \\
\hline Delme hızı & $\mathrm{B}$ & $\mathrm{m} / \mathrm{dak}$ & 50 & 75 & 100 \\
\hline İlerleme & $\mathrm{C}$ & $\mathrm{mm} / \mathrm{dak}$ & 75 & 100 & 150 \\
\hline
\end{tabular}

Sürtünmeli delme deneyleri Microcut Challenger 2414 marka dik işlem merkezli CNC freze tezgâhında yapılmıştır. İş parçası CNC tezgâhının tablasına mengene yardımıyla bağlanarak delikler, hazırlanan CNC programı yardımıyla otomatik olarak delinmiştir(Şekil 1.1). Delme işlemleri kuru ortamlarda yapılmış olup matkap uçlarında herhangi bir yağlayıcı kullanılmamıştır. Deliklerin ortalama yüzey pürüzlülükleri(Ra) Mitutoyo Surftest SJ-201 marka yüzey pürüzlülük cihazı kullanılarak ölçülmüştür. Yüzey pürüzlülüğünü belirlenmesinde 3 farklı deliğin 3 farklı noktasından eksenleri boyunca ölçümler yapılarak ve elde edilen değerlerin ortalamaları alınmıştır. Kovan yükseklik ölçümlerinde $1 \mu \mathrm{m}$ ölçme hassasiyetine sahip Alliton XJP 600 marka ölçme mikroskobu kullanılmıştır. Her bir deney parametresini belirlemek için üç farklı deliğin maksimum yüksekliklerinin ortalaması alınmıştır(Şekil 2.2). Ayrıca delme esnasında matkap iş parçası temas bölgesinin maksimum sıcaklıkları IMPAC IGA 15 Plus marka enfraruj termometre yardımıyla ölçülmüştür.

Delme parametrelerini çoklu performans üzerindeki etkileri hakkında fikir sahibi olmak için özellikle tasarlanmış bir test tekniği gereklidir. Genel olarak, geleneksel bir test tasarımı kullanmak çok karmaşık ve zordur. Ek olarak, fazla değişken varsa daha fazla test yapılması gerekir $[17,18]$.Bu nedenle deneysel çalışmalar için en uygun tasarım Taguchi ortogonal deney tasarımıdır. Bu çalışmada sürtünmeli delme işlemindeki ideal işleme değişkenlerini belirlemek amacıyla Taguchi'nin L9 ortogonal deney tasarımı oluşturuldu (Tablo 3).
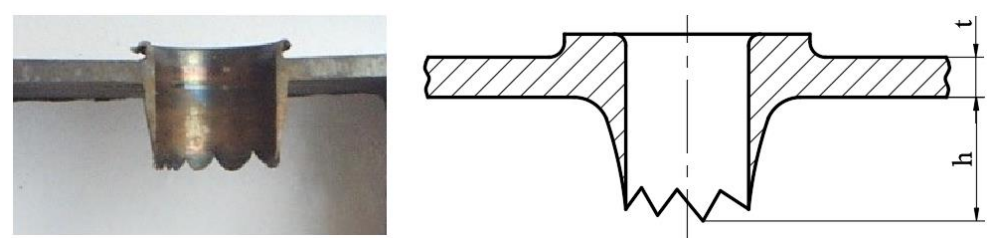

Şekil 2.2. Delik kovan ölçüsü 
Tablo 3. Taguchi L9 ortogonal deneysel tasarım dizisi

\begin{tabular}{cccccc}
\hline Deney No & A & B & C & $\begin{array}{c}\text { Yüzey Pürüzlülüğ̈̈ } \\
\mathbf{R a}(\boldsymbol{\mu m})\end{array}$ & $\begin{array}{c}\text { Kovan yüksekliği } \\
\mathbf{h}(\mathbf{m m})\end{array}$ \\
\hline 1 & 1 & 1 & 1 & 0,52 & 5,5 \\
2 & 1 & 2 & 2 & 0,42 & 5,62 \\
3 & 1 & 3 & 3 & 0,34 & 5,62 \\
4 & 2 & 1 & 2 & 0,53 & 5,29 \\
5 & 2 & 2 & 3 & 0,41 & 5,3 \\
6 & 2 & 3 & 1 & 0,5 & 5,7 \\
7 & 3 & 1 & 3 & 0,52 & 5,08 \\
8 & 3 & 2 & 1 & 0,58 & 5,5 \\
9 & 3 & 3 & 2 & 0,5 & 5,45 \\
\hline
\end{tabular}

\subsection{Deneysel Sonuçlar}

Şekil 4 incelendiğinde sürtünmeli delme işlemlerinde en yüksek yüzey pürüzlülük değerleri düşük ilerleme ve delme hızlarında elde edildiği görülebilir. $75 \mathrm{~m} /$ dak delme hızı ve $30^{\circ}$ sürtünme açısı için ortalama yüzey pürüzlülükleri $50 \mathrm{~mm} /$ dak ilerlemede $0,52 \mu \mathrm{m}, 150 \mathrm{~mm} /$ dak ilerlemede $0,48 \mu \mathrm{m}$ olurken $225 \mathrm{~mm} /$ dak ilerlemede yaklaşık \%15 azalarak $0,45 \mu \mathrm{m}$ elde edilmiştir. İlerlemenin düşük olması takım ile iş parçası arasındaki sıcaklık farkı nedeniyle yumuşayan iş parçasının matkabın soğuk yüzeylerine sıvanmasına neden olmakta ve böylece delik yüzeyini bozmaktadır[10]. Delme hızının yüzey pürüzlülüğüne etkisi incelendiğinde ise $45^{\circ}$ ve $75 \mathrm{~mm} / \mathrm{dak}$ ilerleme için yüzey pürüzlülüğü $50 \mathrm{~m} /$ dak delme hızında $0,62 \mu \mathrm{m}$ iken $100 \mathrm{~m} /$ dak delme hızında yaklaşık \%20 azalarak $0,50 \mu \mathrm{m}$ olmuştur. Şekil 5'deki sıcaklık grafiği incelendiğinde $45^{\circ}$ sürtünme açısı ve $75 \mathrm{~mm} /$ dak ilerleme değeri için $50 \mathrm{~m} /$ dak delme hızında takım temas bölgesi sıcaklığı $695^{\circ} \mathrm{C}$ iken $100 \mathrm{~m} /$ dak delme hızında yaklaşık $\% 16$ artarak $840^{\circ} \mathrm{C}$ olmuştur. Delme hızının artması birim zamanda takım- iş parçası arasındaki sürtünme miktarını artırarak sıcaklığı önce aşırı yükseltir. Bunun neticesinde takımla temas halinde bulunan delik yüzeyinin ince katmanı eriyerek sıvı tabakası oluşmaktadır[4]. Oluşan bu sıvı tabakası bir yağlama görevi yaparak sürtünmeyi azaltmakta ve yüzey pürüzlülüğünü düşürmektedir. Matkap uç sürtünme açısının artması yüzey pürüzlülüğü artırmıştır. $150 \mathrm{~mm} /$ dak ilerleme ve $100 \mathrm{~m} /$ dak delme hızı için $30^{\circ}$ sürtünme açısında $0,38 \mu \mathrm{m}, 45^{\circ}$ sürtünme açısında $0,45 \mu \mathrm{m}$ ve $60^{\circ}$ sürtünme açısında yaklaşık $\% 13$ artarak $0,50 \mu \mathrm{m}$ olmuştur. Aynı şekilde sıcaklık grafiği incelendiği ise 30,45 ve $60^{\circ}$ sürtünme açıları için sırasıyla sıcaklıklar azalarak 801,789 ve $743^{\circ} \mathrm{C}$ elde edilmiştir. Şekil 4'deki delik kovan yüksekliği incelemelerine göre delme hızı artıkça kovan yüksekliği artmakta, buna karşılık ilerleme arttıkça kovan yüksekliği azalmaktadır. $75 \mathrm{~mm} /$ dak ilerleme ve $45^{\circ}$ matkap sürtünme açısı için ortalama kovan yükseklikleri $50 \mathrm{~m} /$ dak delme hızı için $5,4 \mathrm{~mm}, 75 \mathrm{~m} /$ dak delme hızı için 5,56 mm ve $100 \mathrm{~m} / \mathrm{dak}$ delme hızı için 5,7 mm elde edilmiştir. Şekil 5'deki grafiğe göre delme hızının artması takım- iş parçası arasında birim zamandaki sürtünme miktarını artırarak sıcaklığı yükseltmiş̧tir. Bunun sonucunda artan takım temas bölgesi sıcaklığı nedeniyle viskoplastik hale gelen iş parçası ilerlemenin etkisi ile daha fazla ektrüze olarak kovan yüksekliğini artırmıştır. Sürtünmeli delme işleminde ilerlemenin kovan yüksekliği üzerindeki etkisi incelendiğinde ise $100 \mathrm{~m} /$ dak delme hızı ve $45^{\circ}$ sürtünme açısı için $75 \mathrm{~mm} /$ dak ilerlemede $5,7 \mathrm{~mm}, 150 \mathrm{~mm} /$ dak ilerlemede 5,55 $\mathrm{mm}$ ve $225 \mathrm{~mm} /$ dak ilerlemede $5,45 \mathrm{~mm}$ elde edilmiştir. İlerlemenin artması iş parçası takım temas bölgesinin sürtünme süresini kısaltarak sürtünme enerjisini ve buna bağlı olarak sıcaklığı azalmaktadır[7,8]. Azalan sıcaklığa bağlı olarak iş parçası daha az viskoplastik hal alarak kovan yüksekliği de azalmaktadır. Sürtünme açısııın kovan yüksekliğine etkisi incelendiğinde $150 \mathrm{~mm} /$ dak ilerleme ve $75 \mathrm{~m} /$ dak delme hızı için $30^{\circ}$ sürtünme açısında 5,62 $\mathrm{mm}, 45^{\circ}$ sürtünme açısında $5,41 \mathrm{~mm}$ ve $60^{\circ}$ sürtünme açısında $5,36 \mathrm{~mm}$ olduğu görülmüş̧ür. Sürtünme açısının artması matkap uç konisinin temas yüzey uzunluğunu kısaltmaktadır. Takım temas yüzey uzunluğunun kısalması Denklem 1'e göre, takım-iş parçası ara yüzeyindeki sürtünme kuvvetini azaltır. Artan sürtünme açısı ile sürtünme kuvvetindeki azalma takım-iş parçası takım ara yüzey sıcaklığını düşürerek delik yüzey pürüzlülüğü artırmaktadır( Şekil 4c,5b.).

$$
\mathrm{F}_{\mathrm{f}}=(\mathrm{Fa} / \sin \alpha / 2) \cdot \mu
$$

Denklemde $F_{f}$ sürtünme kuvvetini(N), $F_{a}$ ilerleme kuvvetini(N), $\alpha$ matkap sürtünme uç açısını ve $\mu$ ise sürtünme katsayısını ifade etmektedir. 


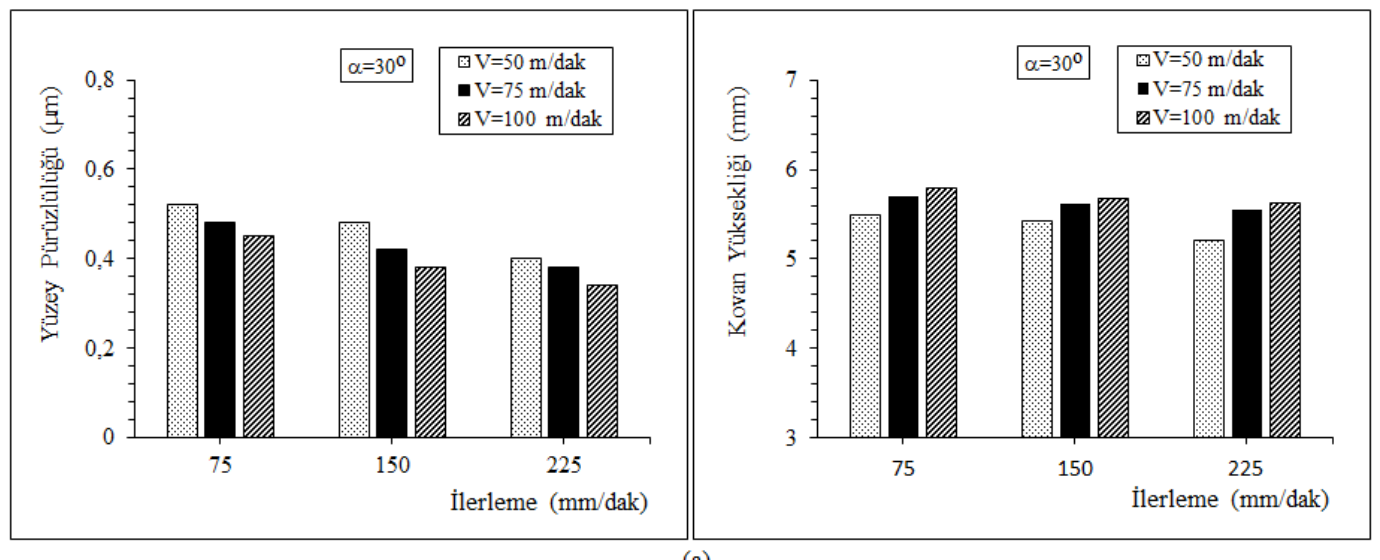

(a)

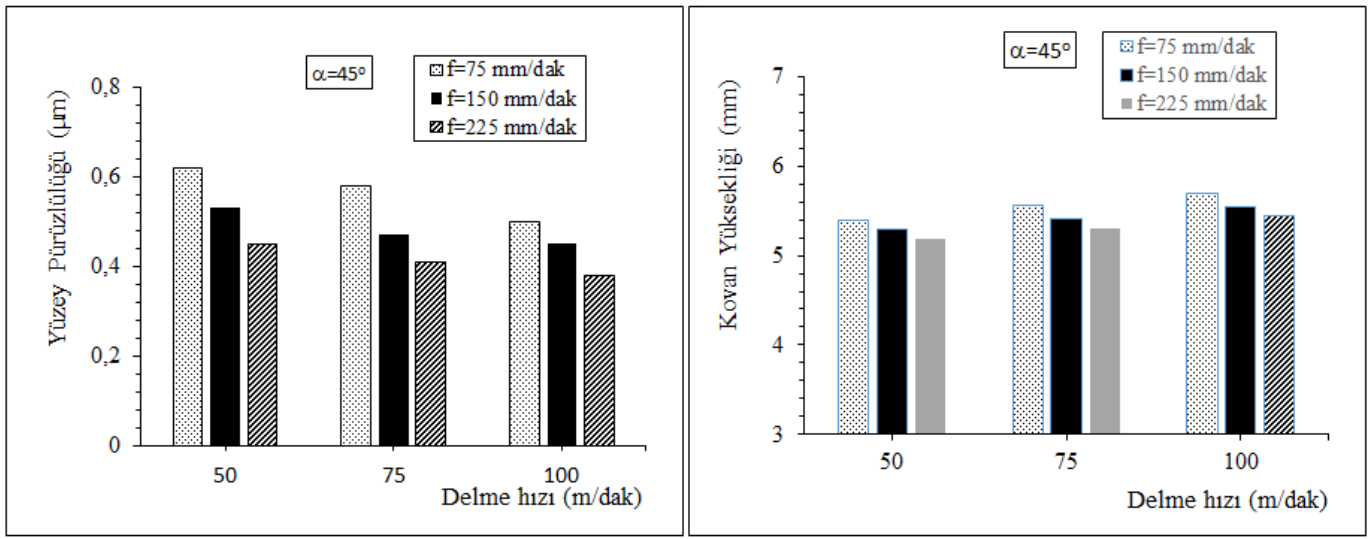

(b)

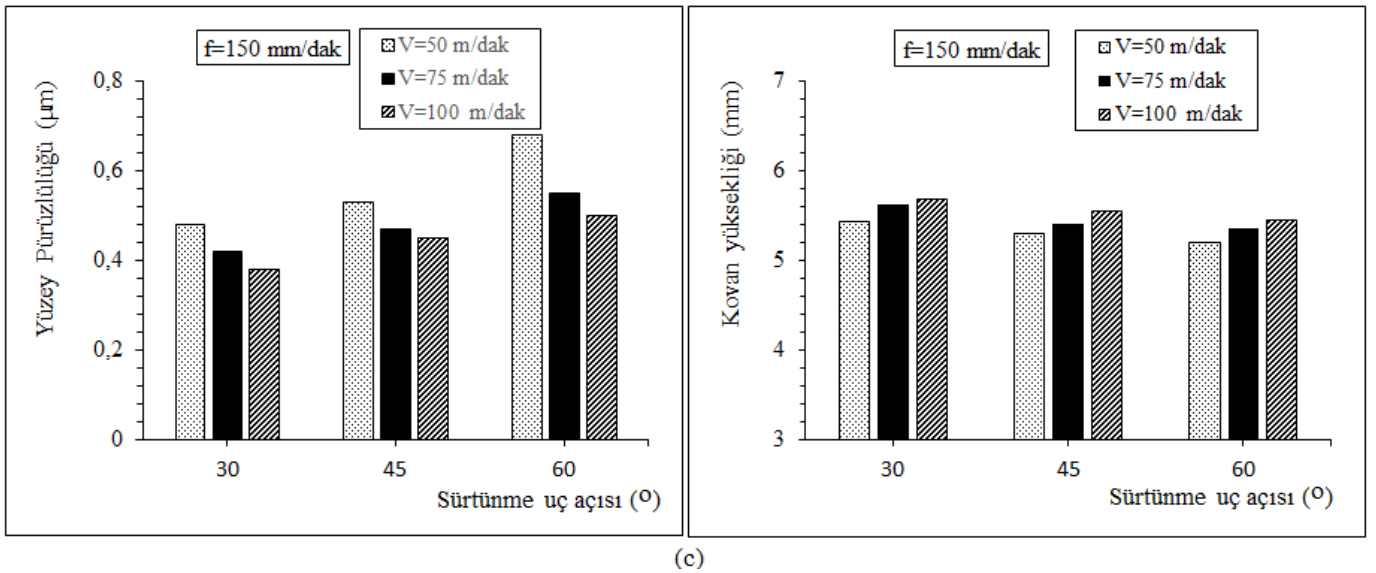

Şekil 4. Delme parametrelerinin delik kovan yüksekliğine ve yüzey pürüzlülüğüne etkisi 


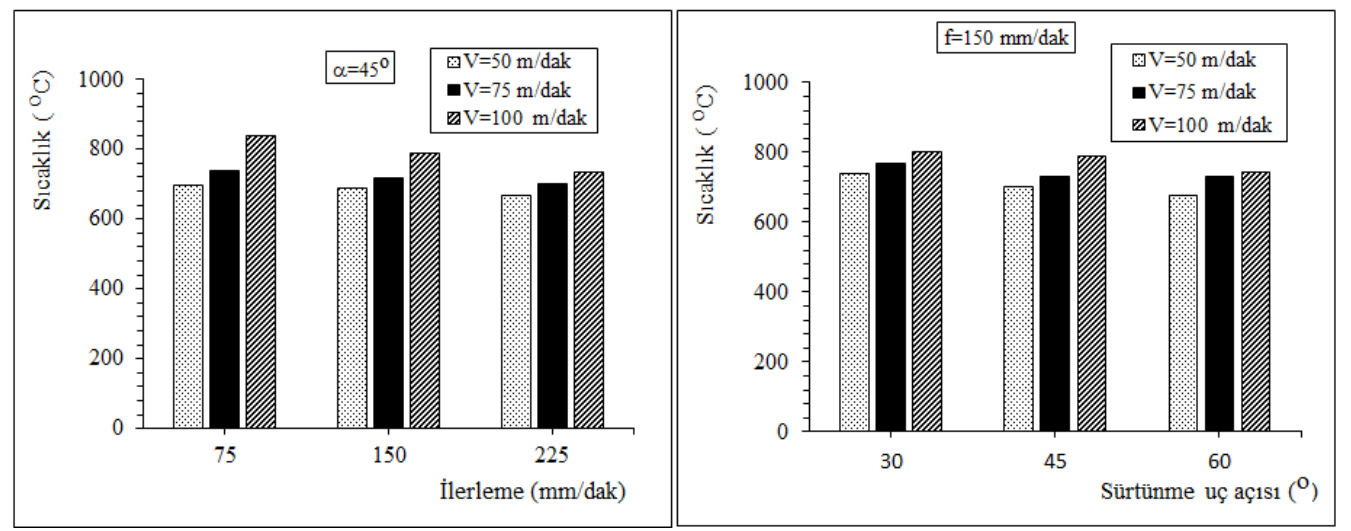

Şekil 5. Delme Parametrelerinin sıcaklık üzerindeki etkisi

\section{Gri İlişkisel Analiz Yöntemi}

Gri İlişki analizi(GRA), ana parametre ile diğer tüm değişken parametreler arasındaki belirsiz ilişkiyi bir sistemde inceleyen etkili bir ölçüm yöntemidir. Deng [17]tarafindan ortaya konan Gri ilişki analizi renkler bilginin derecesini ifade eden Gri sistem teorisine dayanmaktadır. Siyah bilinmeyen bilgiyi, beyaz bilinen bilgiyi, gri ise kısmen bilinen ve kısmen bilinmeyen bilgiyi temsil etmektedir[18-20]. Karmaşık çok değişkenli sistemde farklı faktörler arasındaki ilişki genellikle belirsizdir. Bu sistem genellikle belirsiz, zayıf ve tamamlanmamış bilgileri birleştiren "gri" olarak adlandırılır. Gri sistem doğrudan gerçek verilerle ilgilenir ve tarihin kendine özgü düzenini arar. Gri yöntem, deneyler belirsiz olduğunda ya da deneysel yol düzgün şekilde yapılamadığında istatistiksel analizde eksikler için tek başına yardımcı olur[17,18]. Gri sistem teorisinde serideki noktaların küçük değerler olması isteniyorsa küçük değer alan noktalar lineer normalizasyonda " 1 " e yakın değerler alırken, büyük değer alan noktalar "0" 'a yakın değerler alır. Gri sistem teorisinde daha yüksek daha iyi" durumunda normalizasyon aşağıdaki gibidir;

$$
x_{i}^{*}(k)=\frac{x_{i}^{o}(k)-\min x_{i}^{o}(k)}{\max x_{i}^{o}(k)-\min x_{i}^{o}(k)}
$$

"Daha düşük daha iyi" durumunda ise normalizasyon aşağıdaki gibidir;

$$
x_{i}^{*}(k)=\frac{\max x_{i}^{o}(k)-x_{i}^{o}(k)}{\max x_{i}^{o}(k)-\min x_{i}^{o}(k)}
$$

$x_{i}^{o}$, i serisi k. sıradaki orjinal değer, $x_{i}^{*}(k)$ normalizasyon sonrası i. seri k. sıradaki değer, max $x_{i}^{o}(k)$ i serisindeki maksimum değer, min $x_{i}^{o}(k)$ i serisindeki minimum değerdir.

Verilerin ön hesaplanmasından sonra, gerçek ve ideal normalize edilmiş deneysel sonuçlar arasındaki ilişkiyi ifade edecek şekilde Gri İlişki Katsayısı (GRC) aşağıdaki şekilde hesaplanır:

$$
\xi_{i}(k)=\frac{\Delta_{\min }+\zeta \Delta_{\max }}{\Delta_{o i}(k)+\zeta \Delta_{\max }}
$$

Burada, $\xi_{\mathrm{i}}(\mathrm{k})$ i. deney içerisindeki k. performans çıktıları için gri ilişki katsayısıdır. $\zeta$ ayırt edici katsayı olup $\Delta_{o i}$ ile $\Delta_{m a} x$ arasındaki farkı ayarlar ve genellikle $0<\zeta<1$ aralığında olup genellikle 0,5 alınması tavsiye edilmektedir[21,22]. Denklem 4 'teki $\Delta_{0 i}(\mathrm{k})$ referans ve karşılaştırma sonuçlarındaki sapmadır.

$$
\begin{aligned}
& \Delta_{0 i}(k)=\left\|x_{0}^{*}(k)-x_{i}^{*}(k)\right\| \\
& \Delta_{\text {min }}=\min _{\forall j \in i} \min _{\forall k}\left\|x_{0}^{*}(k)-x_{j}^{*}(k)\right\| \\
& \Delta_{\max }=\max _{\forall j \in i} \max _{\forall k}\left\|x_{0}^{*}(k)-x_{j}^{*}(k)\right\|
\end{aligned}
$$


Gri sistem teorisi disiplinler arası bir bilimsel alandır ve GRA'da iki sistem veya sonuç arasındaki ilişkisel derecenin ölçüsü Gri ilişkisel derece(GRG) ile tanımlanır. Daha büyük bir GRG, karşılık gelen performans çıktılarının ideal normalleştirilmiş değere daha yakın olduğunu gösterir. GRG, gri ilişkisel katsayının ortalama değeri alınarak elde edilir[17,18,20]. GRG Denklem 3 ile hesaplanabilir.

$$
\gamma_{i}=\frac{1}{n} \sum_{k=1}^{n} \xi_{i}(k)
$$

Burada, $\xi_{\mathrm{i}}(\mathrm{k})$ i’inci deney içerisindeki k’inci performans çıktıları için gri ilişki katsayısıdır. Bununla birlikte, farklı işlem parametrelerinin sistemdeki önemi gerçek mühendislik sistemi içinde değişiyorsa, çeşitli parametreler tarafından elde edilen eşit olmayan ağırlık gerçek disiplini içinde GRG, aşağıdaki gibi genişletilebilir[17,18]:

$$
\gamma_{i}=\sum_{k=1}^{n} w_{k} \xi_{i}(k) \quad \sum_{k=1}^{n} w_{k}=1
$$

Burada $w_{k}, k$ faktörü için normalize edilmiş ağırlığı sembolize eder.

\subsection{Gri İlişkisel Analiz Sonuçları}

Sürtünmeli delme işleminde delme verimliliğini artırmak ve işlenen parçaların kalitesini iyileştirmek için en uygun delme koşullarını belirlemek gerekir. En uygun delme koşullarının belirlenmesi yani malzemenin ekonomik ve daha düzgün işlenebilmesi için bir takım bilimsel teknikler geliştirilmiştir. Bunlardan biri de gri ilişkisel analiz yöntemidir. Sürtünmeli delme işleminin optimizasyonu ile ilgili yapılan çalışmalarda varyans analizi(ANOVA) ve bulanık mantık tekniği (Fuzzy Logics ) kullanılarak AISI 304 çeliğin optimizasyonu yapılmıştır. Elde edilen optimizasyon sonuçlarına göre uç konikliğinin yüzey pürüzlülüğü üzerinde önemli etkiye sahip olduğu ve genellikle $30^{\circ}$ ve $45^{\circ}$ sürtünme açılarında optimum değerler aldığı ifade edilmiştir. Ayrıca yüksek devir sayılarında daha düşük yüzey pürüzlülüğünün elde edildiği ve $100 \mathrm{~mm} /$ dak ilerleme değerinin optimum olduğu bildirilmiştir[14,16,23].

Sürtünmeli delme işlemi için delik yüzey pürüzlülüğünün en düşük ve kovan yüksekliğinin en yüksek olması tercih edilir. Bu yöntemde küçük yüzey pürüzlülüğü değerleri için "daha düşük d büyük kovan yükseklikleri için ise "daha büyük daha iyi" yaklaşımına göre normalize edilmiştir[18-20]. Normalizasyon işleminde kovan yükseklikleri ve ortalama yüzey pürüzlülük için sırasıyla Denklem 2 ve 3 kullanılarak 1-9 arası tüm değişkenler için normalizasyon elde edilmiş ve Tablo 4' de verilmiştir.

Tablo 4. Performans özellikleri için normalizasyon sonuçları

\begin{tabular}{cllll}
\hline \multirow{2}{*}{$\begin{array}{c}\text { Deney } \\
\text { No. }\end{array}$} & \multicolumn{2}{l}{ Karşılaştırılan Sonuçlar * } & \multicolumn{2}{l}{ Sapma Sonuçlar } \\
\cline { 2 - 5 } & $\mathrm{R}_{\mathrm{a}}$ & $\mathrm{h}$ & $\mathrm{R}$ & $\mathrm{h}$ \\
\hline 1 & 0,25 & 0,6774 & 0,75 & 0,3226 \\
2 & 0,6667 & 0,871 & 0,3333 & 0,129 \\
3 & 1,0 & 0,871 & 0 & 0,129 \\
4 & 0,2083 & 0,3387 & 0,7917 & 0,6613 \\
5 & 0,7083 & 0,3548 & 0,2917 & 0,6452 \\
6 & 0,3333 & 1,0 & 0,6667 & 0 \\
7 & 0,25 & 0 & 0,75 & 1 \\
8 & 0 & 0,6774 & 1 & 0,3226 \\
9 & 0,3333 & 0,5968 & 0,6667 & 0,4032 \\
\hline$* \mathrm{R}_{\mathrm{a}}$ & ve & $\mathrm{h}=1$ için referans sonuç \\
\hline
\end{tabular}

Ortalama yüzey pürüzlülüğü ve kovan yüksekliği için gerçek ve ideal normalize edilmiş deneysel sonuçlar arasındaki ilişkiyi ifade eden Gri ilişki katsayıları Denklem 4 yardımıyla elde edilmiştir(Tablo 5). Tablo 5 de verilen katsayı matrisi değerlerinin ortalaması Gri ilişkisel dereceyi vermekte ve Denklem 8 ve 9 kullanılarak hesaplanmaktadır.

En düşük yüzey pürüzlülüğü ve en yüksek kovan yüksekliği oluşturan en iyi delme değişkenlerini belirlenmesinde, işlem değişkenlerinin tüm seviyeleri için ortalama GRD belirlenmesinde Taguchi'nin cevap tablosu kullanılmıştır. Ortogonal dizinin bütün sütunlarındaki faktör seviyeli Gri ilişkisel dereceler ve onların ortalama değeri işlemini içermektedir. Delme işlemi değişkenlerinin bütün seviyeleri için Gri ilişkisel dereceler 
benzer yolla elde edilmiştir. Gri İlişkisel derecelerinin maksimum değerinin, karşılaştırma sonucunun referans sonucuyla güçlü bir ilişkiye sahip olduğunu gösterir[18,19,24]. Yani en büyük Gri ilişkisel derecesi değeri, performans çıktıları kategorisini göz ardı ederek en iyi performansı gösterir[25]. Gri İlişkisel Analiz sonucuna göre hem küçük yüzey pürüzlülüğünün hem de büyük kovan yüksekliğinin elde edildiği optimum işlem parametreleri $30^{\circ}$ sürtünme açısı, $100 \mathrm{~m} /$ dak delme hızı ve $225 \mathrm{~mm} /$ dak ilerleme değerlerinden oluşmuştur(Tablo 5). Ayrıca Gri İlişkisel Analizi ile elde edilen optimizasyon sonuçları literatürdeki AISI 304 malzemesinin delinmesi ilgili olarak fuzzy logic ve Anova tekniği ile yapılan optimizasyon çalışmalarıyla da uyumludur[16,23].

Table 5. Hesaplanan gri ilişkisel katsayısı, derecesi ve sıralaması

\begin{tabular}{cccccccc}
\hline \multirow{2}{*}{$\begin{array}{l}\text { Deney } \\
\text { No }\end{array}$} & & & & \multicolumn{2}{c}{ Gri ilişkisel katsayıları } & \multirow{2}{*}{$\begin{array}{c}\text { Gri ilişkisel } \\
\text { derecesi }\end{array}$} & Sıralama \\
\hline 1 & 1 & 1 & 1 & 0.954 & 1 & $\mathbf{h}$ & \\
2 & 1 & 2 & 2 & 0.515 & 0.424 & 0,2520 & 5 \\
$\mathbf{3}$ & $\mathbf{1}$ & $\mathbf{3}$ & $\mathbf{3}$ & $\mathbf{0 . 3 3 3}$ & $\mathbf{0 . 3 4 8}$ & $\mathbf{0 , 4 4 8 7}$ & 3 \\
4 & 2 & 1 & 2 & 0.585 & 0.337 & 0,2044 & $\mathbf{1}$ \\
5 & 2 & 2 & 3 & 0.360 & 0.338 & 0,2670 & 8 \\
6 & 2 & 3 & 1 & 0.896 & 0.337 & 0,3571 & 2 \\
7 & 3 & 1 & 3 & 0.395 & 0.333 & 0,1833 & 9 \\
8 & 3 & 2 & 1 & 1 & 0.337 & 0,2353 & 7 \\
9 & 3 & 3 & 2 & 0.558 & 0.333 & 0,2354 & 6 \\
\hline \multicolumn{8}{c}{ *En düşük Ra ve en yüksek h değerinin elde edildiği deney şartları } \\
\hline
\end{tabular}

Şekil 6'de işlem değişkenlerinin tüm seviyelerinin çoklu performans çıktıları üzerindeki ana etkisini (ortalama yüzey pürüzlülüğ̈̈ ve kovan yüksekliği) gösterilmiştir. Grafikte dikeye en yakın olan değer en etkili değerlerdir. Sürtünmeli delme işlemi için çoklu performans çıktıları üzerinde en etkin seviyeler A1 $\left(30^{\circ}\right)$, B3(100 m/dak) ve C3 $(225 \mathrm{~mm} / \mathrm{dak})$ şeklinde elde edilmiştir.

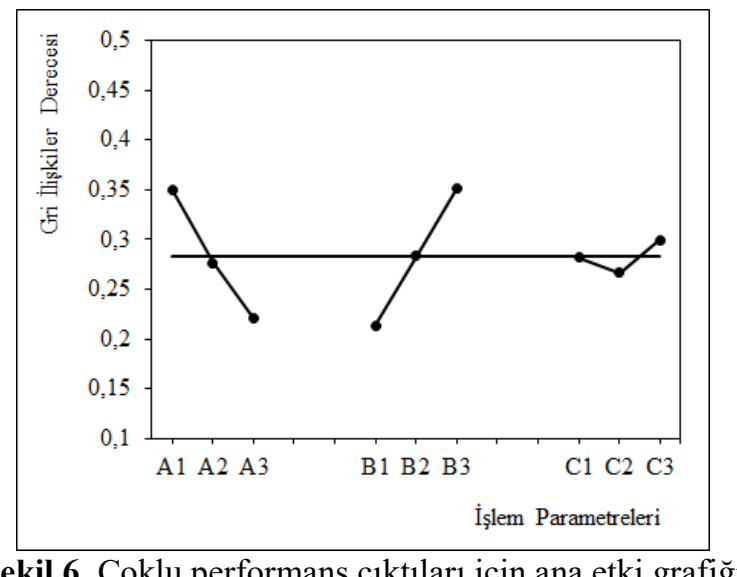

Şekil 6. Çoklu performans çıktıları için ana etki grafiği

Performans göstergesi olarak kullanılan özellikler üzerinde en fazla etkiye sahip olan faktörü belirlemek için elde edilen değerler birbirleri ile karşılaştırılır. Kontrol edilebilir değişkenlerin çoklu performans özellikleri üzerindeki anlamlılık düzeyi bu karşılaştırma ile belirlenmektedir. Diğer taraftan bu veriler incelenerek değişken deney parametrelerinin her birinin çoklu performans çıktıları üzerindeki etkisi elde edilebilir[18]. Ortalama gri ilişkisel derecelerinin maksimum ve minimum değerler arasındaki farklar anlamllık düzeyini belirler. Tablo 6'daki hesaplamaya göre anlamlılık düzeyleri delme hızı(A) için 0,128, ilerleme(B) için 0,137 ve takım sürtünme açısı(C) için 0,033 elde edilmiştir. Bu hesaplamalarda en yüksek anlamlılık düzeyine sahip yüksek fark(ortalama gri ilişkisel dereceler farkı) en etkili faktörü ifade etmektedir. Buna göre en büyük anlamlılık düzeyi 0,137 olup delme parametreleri arasında B faktörünün(ilerlemenin) en etkili olduğunu göstermektedir. Sürtünmeli delme işleminde değişken işlem parametrelerinin çoklu performans üzerindeki önemi sırası, faktör $\mathrm{B}_{3}(100 \mathrm{~m} / \mathrm{dak})$, faktör $\mathrm{A}_{1}\left(30^{\circ}\right)$ ve faktör $\mathrm{C}_{3}(225 \mathrm{~mm} / \mathrm{dak})$ yani $0.137>0.128>0.033$ olarak sıralanabilir. Elde edilen bu sonuçlar delme 
parametrelerinden delme hızının çoklu performans çıktıları üzerinde en fazla etkiye sahip olduğunu, ilerlemenin ise en az etkiye sahip olduğunu göstermektedir.

Table 6. Gri ilișkisel derece için cevap tablosu

\begin{tabular}{|c|c|c|c|c|}
\hline \multirow{2}{*}{$\begin{array}{l}\text { Delme } \\
\text { parametreleri }\end{array}$} & \multicolumn{3}{|c|}{ Faktör seviyesine göre ortalama gri ilişsisel derece } & \multirow{2}{*}{$\begin{array}{c}\text { Anlamlılık düzeyi } \\
\text { (Max-Min) }\end{array}$} \\
\hline & 1.Seviye & 2.Seviye & 3.Seviye & \\
\hline A & $0,349799 *$ & 0,276202 & 0,221388 & 0,128411 \\
\hline B & 0,213236 & 0,283687 & $0,350466^{*}$ & 0,13723 \\
\hline $\mathrm{C}$ & 0,281466 & 0,266222 & $0,29970^{*}$ & 0,03348 \\
\hline
\end{tabular}

*En yüksek etkiye sahip parametre seviyeleri

\section{Sonuçlar}

Delme hızı arttıkça matkap ucunun birim zamanda iş parçasına temas süresi arttığından sıcaklık yükselmekte ve yüzey pürüzlülüğü düşerek kovan yüksekliğini artmaktadır. Artan sıcaklık iş parçasının daha fazla viskoplastik hale getirerek ilerlemenin etkisi ile iş parçası daha fazla ektrüze olmaktadır. Ayrıca yüksek delme hızlarında sıcaklık önce aşırı bir şekilde yükselmekte ve takımla temas halinde bulunan delik yüzeyindeki ince katman eriyerek sıvı tabakası oluşmaktadır. Oluşan bu sıvı tabakası bir yağlama görevi yaparak sürtünmeyi ve buna bağlı olarak yüzey pürüzlülüğünü düşürmektedir.

İlerlemenin artması yüzey pürüzlülüğünü ve kovan yüksekliğini düşürmektedir. İlerleme artması delik bölgesindeki sıcaklık azalmakta ve buna bağlı olarak kovan yüksekliğini düşürmektedir. Buna karşılık artan ilerleme, takım-iş parçası ara yüzeyinde oluşan sıcaklığın ani olarak düşmesine ve takım ile delik yüzeyindeki ince sıvı tabakasının katılaşmasına zaman tanımadığından yüzey pürüzlülüğü azaltmaktadır.

Sürtünme açısının artması delme esnasında iş parçası ile takım arasında oluşan sürtünme yüzeyinin azalmasına neden olur. Bu durum takım-iş parçası temas yüzey sıcaklığını düşürerek yüzey pürüzlülüğü ve kovan yüksekliğini azaltmaktadır. Ayrıca sürtünme açısının artması sürtünme kuvvetini azaltarak takım-iş parçası temas süresini sıcaklığg düşürmektedir.

Minimum Ra yüzey pürüzlülüğü, maksimum kovan yüksekliğini veren sürtünmeli delme parametreleri Taguchi metodunun ile birlikte Gri İlişkisel Analiz yönteminin kullanılmasıyla da çok amaçlı olarak başarılı bir şekilde optimize edilmiştir. İdeal delme parametreleri için çoklu performans cevap tablosunun en yüksek Gri ilişkisel derecesi ideal delme parametrelerini göstermektedir. Sürtünmeli delme işlemi için minimum yüzey pürüzlülüğünün ile maksimum kovan yüksekliğinin birlikte elde edildiği optimum delme parametreleri $30^{\circ}$ sürtünme açısı, $100 \mathrm{~m} /$ dak delme hızı ve $225 \mathrm{~mm} /$ dak ilerleme olarak elde edilmiştir.

Sürtünmeli delmede deney parametre seviyelerinin çoklu performans çıktıları üzerindeki etkisi GRG ile belirlenebilmektedir. İşlem parametrelerinin çoklu performans karakterleri üzerindeki önemi sırası, faktör $\mathrm{B}_{3}(100$ $\mathrm{m} /$ dak $)$, faktör $\mathrm{A}_{1}\left(30^{\circ}\right)$ ve faktör $\mathrm{C}_{3}(225 \mathrm{~mm} /$ dak $)$ yani $0.137>0.128>0.033$ olarak siralanmaktadır. Elde edilen bu sonuçlara göre çoklu performans çıktıları üzerinde en fazla etkili olan deney parametresi delme hızı, en az etkili olan parametre ise ilerleme olarak belirlenmiştir.

\section{Kaynaklar}

[1] Cantero JL, Tardío MM, Canteli JA, Marcos M, Miguélez MH. Dry drilling of alloy Ti-6Al-4V. Int J Mach Tools Manuf 2005. doi:10.1016/j.ijmachtools.2005.01.010.

[2] Zurrayen M, Mutalib A, Idris M, Ismail S, Aswan N, Jalil A, et al. Characterization of tool wear in friction drilling. J Tribol 2018;17:93-103.

[3] Miller SF, Shih AJ. Thermo-Mechanical Finite Element Modeling of the Friction Drilling Process. J Manuf Sci Eng 2007. doi:10.1115/1.2716719.

[4] Chow HM, Lee SM, Yang LD. Machining characteristic study of friction drilling on AISI 304 stainless steel. J Mater Process Technol 2008;207:180-6. doi:10.1016/j.jmatprotec.2007.12.064.

[5] Lee SM, Chow HM, Huang FY, Yan BH. Friction drilling of austenitic stainless steel by uncoated and PVD AlCrN- and TiAlN-coated tungsten carbide tools. Int J Mach Tools Manuf 2009;49:81-8. doi:10.1016/j.ijmachtools.2008.07.012.

[6] Miller SF, Blau PJ, Shih AJ. Tool wear in friction drilling. Int J Mach Tools Manuf 2007;47:1636-45. doi:10.1016/j.ijmachtools.2006.10.009.

[7] Lee SM, Chow HM, Yan BH. Friction drilling of IN-713LC cast superalloy. Mater Manuf Process 2007;22:893-7.

[8] Ozler L, Dogru N. An experimental investigation of hole geometry in friction drilling. Mater Manuf Process 2013;28:470 
5. doi:10.1080/10426914.2012.746699.

[9] Miller SF, Tao J, Shih AJ. Friction drilling of cast metals. Int J Mach Tools Manuf 2006;46:1526-35. doi:10.1016/j.ijmachtools.2005.09.003.

[10] Demir Z, Özek C. Investigate the effect of pre-drilling in friction drilling of A7075-T651. Mater Manuf Process 2014. doi:10.1080/10426914.2014.892986.

[11] Dehghan S, Ismail M, Ariffin M, Baharudin B. Experimental investigation on friction drilling of titanium alloy. Eng Solid Mech 2018;6:135-42.

[12] Boopathi M, Shankar S, Manikandakumar S, Ramesh R. Experimental investigation of friction drilling on brass, aluminium and stainless steel. Procedia Eng, 2013. doi:10.1016/j.proeng.2013.09.201.

[13] Eliseev AA, Fortuna S V., Kolubaev EA, Kalashnikova TA. Microstructure modification of 2024 aluminum alloy produced by friction drilling. Mater Sci Eng A 2017. doi:10.1016/j.msea.2017.03.040.

[14] El-Bahloul S, El-Shourbagy H, Al-Makky M, El-Midany T. Thermal Friction Drilling: (A Review). Int Conf Aerosp Sci Aviat Technol 2018;15:1-15. doi:10.21608/asat.2013.22057.

[15] El-Bahloul SA, El-Shourbagy HE, El-Midany TT. Optimization of Thermal Friction Drilling Process Based on Taguchi Method and Fuzzy Logic Technique. Int J Sci Eng Appl 2015;4:54-9. doi:10.7753/ijsea0402.1006.

[16] Ku WL, Hung CL, Lee SM, Chow HM. Optimization in thermal friction drilling for SUS 304 stainless steel. Int J Adv Manuf Technol 2011. doi:10.1007/s00170-010-2899-5.

[17] Deng J-L. Control problems of grey systems. Sys Contr Lett 1982;1:288-94.

[18] Tosun N, Pihtili H. Gray relational analysis of performance characteristics in MQL milling of $7075 \mathrm{Al}$ alloy. Int J Adv Manuf Technol 2010. doi:10.1007/s00170-009-2118-4.

[19] Wen K-L. The grey system analysis and its application in gas breakdown and var compensator finding. Int J Comput Cogn 2004;2:21-44.

[20] Lin Y, Chen M, Liu S. Theory of grey systems: capturing uncertainties of grey information. Kybernetes 2004;33:196218

[21] Taşkesen A, Kütükde K. Experimental investigation and multi-objective analysis on drilling of boron carbide reinforced metal matrix composites using grey relational analysis. Meas J Int Meas Confed 2014. doi:10.1016/j.measurement.2013.08.040.

[22] Bilge T, Motorcu AR, Ivanov A. Optımization of drilling parameters for dimensional accuracy in drilling of compact laminate composite 2017;9:1-22.

[23] El-Bahloul SA, El-Shourbagy HE, El-Bahloul AM, El-Midany TT. Experimental and Thermo-Mechanical Modeling Optimization of Thermal Friction Drilling for AISI 304 Stainless steel. CIRP J Manuf Sci Technol 2018;20:84-92. doi:10.1016/j.cirpj.2017.10.001.

[24] Viswanathan R, Ramesh S, Subburam V. Measurement and optimization of performance characteristics in turning of Mg alloy under dry and MQL conditions. Meas J Int Meas Confed 2018. doi:10.1016/j.measurement.2018.02.018.

[25] Lee SH, Lee S-H. Optimisation of cutting parameters for burr minimization in face-milling operations. Int J Prod Res 2003;41:497-511. 